\title{
Seventy-five years research at Naaldwijk
}

This special issue of Netherlands Journal of Agricultural Science contains a number of papers describing projects carried out at the research station at Naaldwijk. This issue is published to commemorate the 75th anniversary of the research station.

The experimental station 'Westland' was founded officially on 14 August 1900. Its aims were to support horticultural education and to promote production of vegetables and fruit in the Westland area of south-west Holland.

Various experiments on nutrition, varieties, plant protection and cultivation techniques were carried out. The most important crops were tomatoes and grapes.

The first experiments were rather simple, and the station was short of facilities during the first years. Money was scarce at that time, and in 1924 there was even talk of closing down the station. Yet the decision was made to continue the work, and at the same time the station was reorganized. More land was purchased on another site, where a new building was erected in 1925. The present station is still situated here.

The first director, K. Wiersma, was succeeded in 1924 by J. M. Riemens, and under the latter's spirited leadership the research work expanded considerably. The targets also became broader. In 1927, the experimental station started to cater for horticulture in the whole of the South Holland Glasshouse District. Problems of cucumbers - for instance Fusarium - were added to the program.

In the 1930's soil research was developed. A laboratory was equipped for chemical analyses to provide advice to growers. The interest in soil research increased rapidly.

At the end of the 1930's, the Government provided the funds for a new main building which is still being used. The building was opened officially at the beginning of 1941.

The war years again proved to be a difficult time for the station and its staff. However, after the war the station entered a new phase of growth and development. In 1949, the experimental station was given a national task besides its regional status and its name was changed to Proefstation voor de Groenten- en Fruitteelt onder Glas (Glasshouse Crops Research and Experiment Station). Research work was intensified. Since then the staff has practically doubled and is about 150 at present. New facilities were added and at the same time the research programme was enlarged. However, at all times the programme was geared to the problems found on commercial holdings. New commercial developments were furthered or initiated. Soil and nutritional research is still of great importance as is research in plant protection and crop technology.

Climatological research in glasshouses has increased substantially, and expansion has taken place in the field of plant physiology and research on biological pest control and economic and labour problems.

The work is not only applied to the main vegetable crops - tomatoes, cucumbers and lettuce - but also to minor crops like aubergines and peppers, whilst efforts are being made to introduce new crops such as crisp lettuce. 


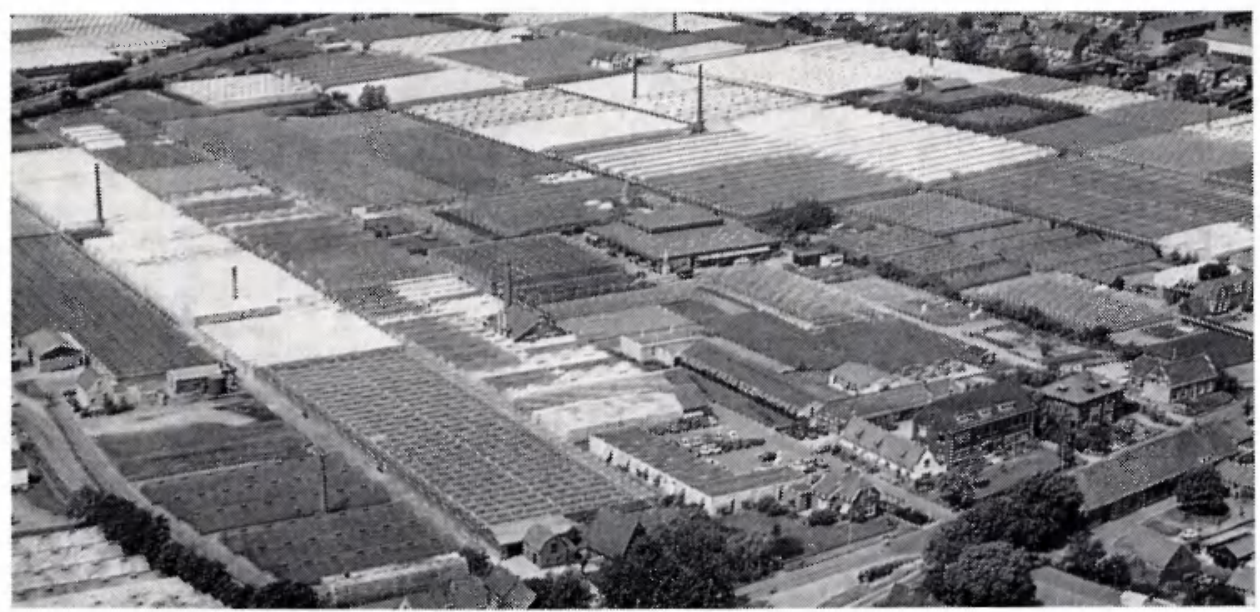

Besides the vegetable crops, various flower crops have been added to the research programme. At present about one quarter of the research capacity is devoted to flowers. This work is carried out in close co-operation with the research station at Aalsmeer. There is also close co-operation with a number of institutes engaged in horticultural research.

The experimental results have often led to substantial increases in productivity and to improvements in the quality of a number of products. The results obtained in different projects and the modern research facilities (multifactorial unit) are described in the following papers. These by no means cover the whole field of research. Nevertheless, they illustrate the wide range of activities in which the research station is engaged.

Ir E. Kooistra 